\title{
Analysis of Engine Propeller Matching of DC Motor as a Main Propulsion
}

\author{
Eddy Setyo Koenhardono ${ }^{1}$, Juniarko Prananda ${ }^{2}$, Ekaprana Danian ${ }^{3}$
}

\begin{abstract}
- the development of ship always searches through the most benefits system for reducing costs of propulsion system without increase pollution. Diesel propulsion system or also known as conventional propulsion system is efficient but requires high operating costs and increase high level of marine pollution. Electrical propulsion system is using electric motors as the prime mover of the propeller. There are 2 types of electric motors that will be used for research of electric propulsion system, there are; DC motors and three-phases induction motor. As the use of DC motor as a prime mover for this electrical propulsion system, this study determines the characteristic between voltage terminal with torque and also field current with torque. It results that torque produced by the DC motor is in the same magnitude with the speed (RPM). The higher the speed have shaped the value of the torque. The input and terminal voltages adjusts all variables and results. In this study, different field voltage creates different pattern of motor envelope. Its manner to propeller curve occurs total different results. With field voltage of $50 \mathrm{~V}$, the ranges of motor envelope immoveable in the point of $150 \%$ of present speed and $160 \%$. While field voltage of $60 \mathrm{~V}$ serves larger ranges of motor envelope which possible to reach further than $50 \mathrm{~V}$ curve.
\end{abstract}

Keywords - DC motor, electric propulsion system, motor envelope, propeller curve, rpm, ship propulsion system, torque.

\section{INTRODUCTION}

$T_{\mathrm{h}}$ he development of ship always searches through the most benefits system for reducing costs of propulsion system without create more pollution. Diesel propulsion system or also known as conventional propulsion system is efficient but requires high operating costs and create high level of marine pollution. Compare with all the alternate propulsion system nowadays the best tried out alternative in recent time is electrical propulsion system.

Electrical propulsion system is using electric motors as the prime mover of the propeller. There are 2 types of electric motors that will be used for research of electric propulsion system, there are; DC motors and three-phase induction motor.

In respond to common used electrical propulsion This research will discuss about analysis engine and propeller matching for electrical propulsion with DC motor as a prime mover. As the use of DC motor as a prime mover for this electrical propulsion system in this research will be discuss about the character relation between voltage terminal with torque and also field current with torque.

As the character, electrical and mechanical of DC motor gained then authors know what is exactly the necessity of DC motor as the prime mover for selecting the engine. To find the proper engine authors can adjust the all variable mentioned before comply the specific of

Eddy Setyo Koenhardono, Department of Marine Engineering, Institut Teknologi Sepuluh Nopember, Surabaya 60111, Indonesia. Email: koenhardono@gmail.com

Juniarko Prananda, Department of Marine Engineering, Institut Teknologi Sepuluh Nopember, Surabaya 60111, Indonesia.

Email: juniarko.prananda@gmail.com

Ekaprana Danian, Undergraduate Program in Department of Marine Engineering, Institut Teknologi Sepuluh Nopember, Surabaya 60111, Indonesia. engine based on the variable input of all the parameter before. For the result authors have to visualize the result of torque by the graphic between power and rpm. The character of the graphic be expected perform by the obtain DC motor suitable as a method of engine propeller matching for electrical propulsion [1-2].

\section{METHOD}

DC machines are generators that convert mechanical energy to electric energy and motors that convert DC electric energy to mechanical energy. Most DC machines are like $\mathrm{AC}$ machines in that they have $\mathrm{AC}$ voltages and currents within them. DC machines have a DC output only because a mechanism exists that converts the internal AC voltages to DC voltages at their terminals. Since this mechanism is called a commutator, DC machinery is also known as commutating machinery.

If the rotor of this machine is rotated, a voltage will be induced in the wire loop. To determine the magnitude and shape of the voltage as shown in Figure 2. The loop of wire shown is rectangular, with sides ab and cd perpendicular to the plane of the page and with sides be and da paraliel to the plane of the page. The magnetic field is constant and perpendicular to the surface of the rotor everywhere under the pole faces and rapidly falls to zero beyond the edges of the poles [3-6].

Typical steady-state volt-ampere characteristics of $\mathrm{dc}$ generators are shown in Figure 1, constant-speed operation being assumed. The relation between the steady- state generated emf Ea and the terminal terminal voltage $\mathrm{Va}$ is as shown in Equation 1.

Consider a pulley of radius $r$ meter acted upon by a circumferential force of $\mathrm{F}$ Newton which causes it to rotate at $\mathrm{N}$ rpm. Then Torque can be defined by Figure 2 and Equation 2. [7-8]

Gross mechanical power developed by a motor is maximum when back emf. is equal to half the applied voltage. This condition is, however, not realized in 
practice, because in that case current would be much beyond the normal current of the motor. The gross mechanical power developed by a motor can be expressed by Equation 3 .

Compared with stationary power plants, there is one big difference with diesel-electric propulsion systems. With the stationary power plants, it's only the load, due to the varying ship speed, which is changing onboard ships. With diesel-electric propulsion the frequency will also change due to the varying propeller speed. [9-11]

\section{A. Statements of Problems}

This stage intended to make describe the outline of this research, all supporting items such as problem and question prepared to specify objective of this research.

\section{B. Literature Study}

Right after the problems is raised, a literature study is performed. In this stage, literature will be used to connect the problems with existing theories and facts from various sources. The study of literature is done by reading papers, journals, research, media and literature books that relates and able to support this research.

\section{Equipment Preparation}

After literature study which support the research has been done, The next stage is prepare all the supporting equipment to which will be use during the experiment such as DC motor shunt, rectifier, regulator, multimeter, tachometer, generator, cable, ampere meter and other supporting equipment.

\section{DC Motor Data Collecting}

This stage is about start from making the circuit to connect the power input to DC motor shunt. On this stage will be prepared all the equipment to perform the observation for the next step.

\section{E. Data Processing}

On this stage, all the result after several data collecting and variable input will be gather and observe is there any mistake or not during the data collecting and also on this stage will be calculated the constant work, power input, power output, and efficiencies. Graphical representative will be performed on this stage to visualize the result. The data from the observation analyzed to verified the character of torque and speed regarding to variation input of voltage to maintain the torque and speed on the different load.

\section{F. Data Collection is adequate for Propulsion System Analysis}

The result from data processing will be determine whether it is capable to be compare to Propulsion System needs or graphic. Thus, will be gather together with Engine Propeller Matching (EPM) characteristic.

\section{G. Analysis of DC Motor Characteristic for Propulsion System}

Correlation of of DC motor characteristic and EPM will be visualize in one conclusion chart. Graphical result will be the output of this stage.

\section{H. Conclusion}

This final stage is intended to resume the result of this research. On this stage will be describe and explain the value of data collecting. Also on this stage questions and problems are answered specifically in order to meet the specific objectives of this research. The conclusion of the research is to fulfill the statement of the problems mentioned earlier.

$>$ The formula for Steady Ea and Terminal Voltage (Va) Correlation:

$V_{a}=E_{a}-I_{a} R_{a}($ watt $)$

$>$ The formula to power development:

$$
P=2 \pi N / 60 \cdot T(\text { watt })
$$

The formula for power output:

$$
P_{\text {out }}=P_{\text {in }}-\left(I_{\text {arm }}^{2} R_{\text {arm }}+I_{f}^{2} R_{f}\right)(\text { watt })
$$

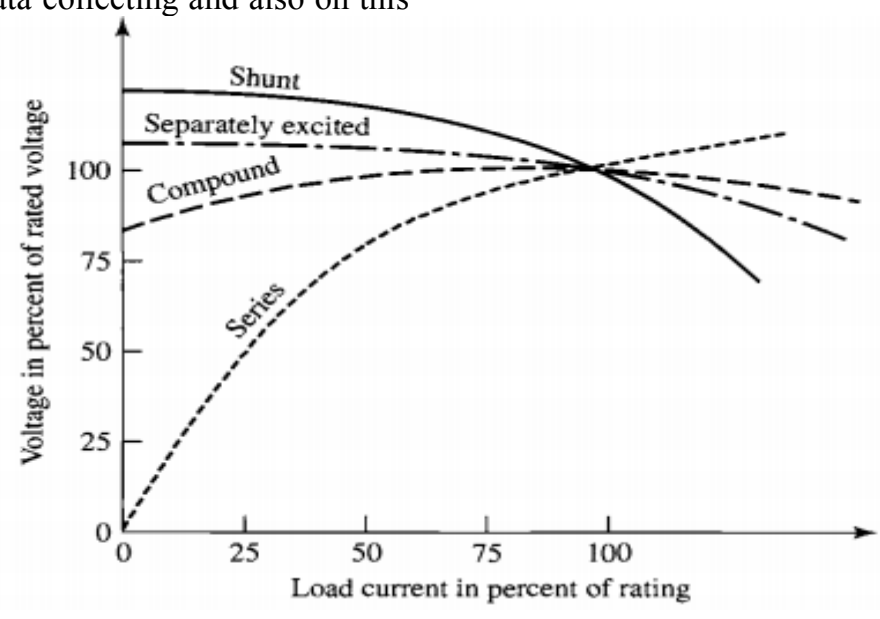

Figure. 1. DC Generator Typical Volt-Ampere Characteristic [2] 


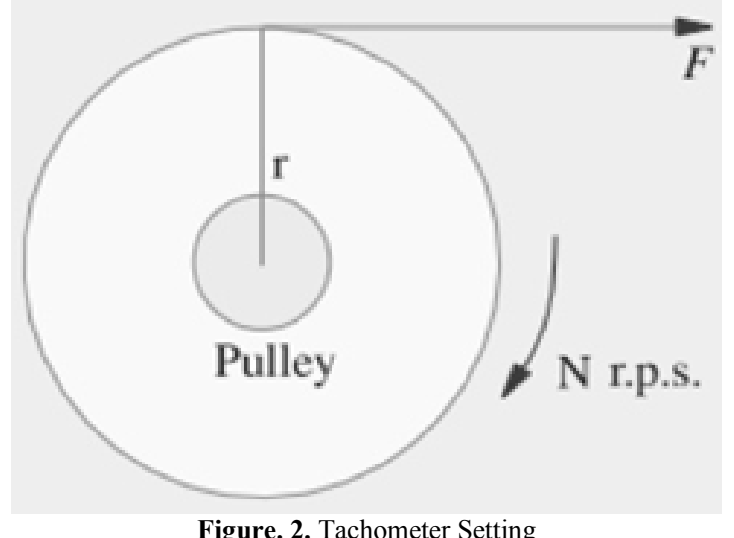

Figure. 2. Tachometer Setting

\section{RESULT AND DISCUSSION}

\section{A. General}

Below listed the sequence of data collecting process;

a. Preparing data collection: gears, motor, generator, cables, regulators, rectifier, and measurement tools (voltmeter and ampere meter).

b. Constructing electrical circuits for data collecting purpose.

c. Connected with the motor, consist two circuits; Terminal and Field. Each circuits needs regulators, rectifier, and cables connected with resistance.

d. Generator placed as resistance inside the operation of the circuits.

e. Measurement tools located within in aim to collect electric voltage and current information.

\section{B. DC Motor Data Collection}

Sort of data gathered in data collecting serves in two different categories, zero load and loaded. Hereby the sample of zero load condition initial data with initial condition field voltage $\left(\mathrm{V}_{\mathrm{F}}\right) 50 \mathrm{~V}$ presented in Table 1 and Table 2 .

\section{Input Power and Losses Variable Calculation}

Input Power (P.in) is the developed power in watt units. It consists of multiplication of current in ampere and electrical equivalent to mechanical power in volt. Besides, losses including in the calculation is terminal copper loss. It is later correlated with electromotive force (EMF) and the power output of DC motor. The variable consist of current in ampere and resistance in ohm. Referred to equations in literature study, the results delivered in Table 3

\section{Electromotive Force (EMF) Calculation}

EMF is electrical equivalent to mechanical power in volt units. In this case, it is necessary to be calculated to acquire terminal electrical equivalent value to its mechanical gain. Referred to equations in literature study, the results delivered in Table 4.

\section{E. Torque, Output Power, and Efficiency Calculation}

In this case of DC motor, terminal torque is to be acquire in order to gain the information of the torque escalation with the speed increase due to the increasing of terminal voltage. Terminal torque consist of multiplication of terminal electromotive force in watt and terminal current in ampere, divided by two times phi speed in rpm and constant of 60 .

Input Power $\left(\mathrm{P}_{\text {.out }}\right)$ is the developed power minus terminal and field losses. It represents the gross mechanical power developed by a motor is maximum after losses being calculated. It correlated to efficiency is comparison between the output power and input power. It represents the effectiveness of the DC motor to deliver the output of the motor through its losses. Those results presented in Table 4.

\section{F. Loaded Condition Pout vs. RPM}

Figure 3 represents $\mathrm{P}_{\text {out }}$ vs. RPM in constant field current 0.32 A. Progression from A to D shown different terminal voltage starting point with constant field voltage of 0.32 ampere. The input voltage increasing from 10 to 30 volt will deliver an increase of terminal voltage as shown in Table IV.3. Its condition represents in graph of output power (W) versus speed (RPM). Shown the torque and RPM is increasing along with starting voltage condition. The light blue trend lines indicates the maximum error of served data collecting comes in scenario $\mathrm{C} 3^{\text {rd }}$ point that shown 7.5 watt above the trend line located in 132.5 watt. It marks $5.66 \%$ of error in scenario $\mathrm{C}$ operating condition.

Figure 4 represents $P_{\text {out }}$ vs. RPM in constant field current 0.38 A. Progression from A to D shown different terminal voltage starting point with constant field voltage of 0.38 ampere. The input voltage increasing from 10 to 30 volt will deliver an increase of terminal voltage as shown in Table IV.3. Its condition represents in graph of output power (W) versus speed (RPM). Shown the torque and RPM is increasing along with starting voltage condition. The light blue trend lines indicates the maximum error of served data collecting comes in scenario $\mathrm{C} 3^{\text {rd }}$ point that shown 5 watt above the trend line located in 152.5 watt. It marks $3.28 \%$ of error in scenario $\mathrm{C}$ operating condition.

\section{G. Motor Propeller Matching}

Modeling process of the propeller curve based on one specific example vessel. It comes as an example just to show the representation of the DC motor characteristic due to the propeller curve. The technical specification of the vessel shown in Table 5. 
International Journal of Marine Engineering Innovation and Research, Vol. 2(1), Dec. $2017.08-15$ (pISSN: 2541-5972, eISSN: 2548-1479)

TABLE 1.

ZERO LOAD CONDITION DATA COLLECTION $(\mathrm{VF}=50 \mathrm{~V})$

\begin{tabular}{ccccccc}
\hline \multicolumn{7}{c}{ Zero Load Condition } \\
\hline Con. & $\mathbf{V}_{\mathbf{F}}(\mathbf{V})$ & $\mathbf{I}_{\text {:arm }}(\mathbf{A})$ & $\mathbf{I . F}(\mathbf{A})$ & $\mathbf{R P M}$ & $\mathbf{V}_{\text {arm }}(\mathbf{V})$ & $\mathbf{V}_{\text {in }}(\mathbf{V})$ \\
\hline $\mathrm{A}$ & 50 & 2.61 & 0.32 & 957 & 40 & $10 \sim 30$ \\
\hline $\mathrm{B}$ & 50 & 2.37 & 0.32 & 1070 & 45 & $10 \sim 30$ \\
\hline $\mathrm{C}$ & 50 & 2.57 & 0.32 & 1178 & 50 & $10 \sim 30$ \\
\hline $\mathrm{D}$ & 50 & 2.68 & 0.32 & 1330 & 55 & $10 \sim 30$ \\
\hline
\end{tabular}

TABLE 2.

LOADED CONDITION DATA COLLECTION $(\mathrm{VF}=50 \mathrm{~V})$

\begin{tabular}{|c|c|c|c|c|c|c|}
\hline \multicolumn{7}{|c|}{ A: Loaded Condition (V.Arm starting 40, V.F constant in $50 \mathrm{~V}$ ) } \\
\hline No. & $V_{\text {in }}(V)$ & $\mathbf{I}_{\mathrm{L}}(\mathbf{A})$ & $\mathbf{I}_{\mathrm{arm}}(\mathrm{A})$ & $\mathbf{I}_{\mathrm{F}}(\mathbf{A})$ & $V_{\text {arm }}(V)$ & $V_{F}(V)$ \\
\hline A-0 & 0 & 0 & 2.55 & 0.32 & 40 & 50 \\
\hline A-1 & 10 & 0.1 & 2.8 & 0.32 & 41 & 50 \\
\hline A-2 & 15 & 0.1 & 3.04 & 0.32 & 42 & 50 \\
\hline A-3 & 20 & 0.2 & 3.37 & 0.32 & 43 & 50 \\
\hline A-4 & 25 & 0.2 & 3.61 & 0.32 & 44 & 50 \\
\hline A-5 & 30 & 0.2 & 3.76 & 0.32 & 45 & 50 \\
\hline No. & $V_{\text {in }}(V)$ & RPM & & & & \\
\hline A- 0 & 0 & 957 & & & & \\
\hline A-1 & 10 & 994 & & & & \\
\hline A-2 & 15 & 993 & & & & \\
\hline A-3 & 20 & 1025 & & & & \\
\hline A-4 & 25 & 1030 & & & & \\
\hline A-5 & 30 & 1046 & & & & \\
\hline
\end{tabular}

TABLE 3.

LOSSES VARIABLE ReSUlt $(\mathrm{VF}=50 \mathrm{~V})$

\begin{tabular}{|c|c|c|c|c|c|c|}
\hline \multicolumn{7}{|c|}{ A: Loaded Condition (V.Arm starting 40, V.F constant in 50 V) } \\
\hline No. & $V_{\text {in }}(V)$ & I.L (A) & I.Arm (A) & I.F (A) & V.Arm (V) & $V_{. F}(\mathrm{~V})$ \\
\hline $\mathrm{A}-0$ & 0 & 0 & 2.55 & 0.32 & 40 & 50 \\
\hline A-1 & 10 & 0.1 & 2.8 & 0.32 & 41 & 50 \\
\hline A-2 & 15 & 0.1 & 3.04 & 0.32 & 42 & 50 \\
\hline A-3 & 20 & 0.2 & 3.37 & 0.32 & 43 & 50 \\
\hline A-4 & 25 & 0.2 & 3.61 & 0.32 & 44 & 50 \\
\hline A-5 & 30 & 0.2 & 3.76 & 0.32 & 45 & 50 \\
\hline No. & $V_{\text {in }}(\mathbf{V})$ & RPM & $P_{\text {.in }}(\mathbf{W})$ & Ia.Ra & $\mathrm{Ia}^{2} \cdot \mathrm{Ra}$ & $\mathbf{I f}^{2} . \mathbf{R f}$ \\
\hline A- 0 & 0 & 957 & 0 & 0 & 0 & 0 \\
\hline A-1 & 10 & 994 & 130.80 & 11.2 & 31.36 & 11.26 \\
\hline A-2 & 15 & 993 & 143.68 & 12.16 & 36.97 & 11.26 \\
\hline A-3 & 20 & 1025 & 160.91 & 13.48 & 45.43 & 11.26 \\
\hline A-4 & 25 & 1030 & 174.84 & 14.44 & 52.13 & 11.26 \\
\hline A-5 & 30 & 1046 & 185.20 & 15.04 & 56.55 & 11.26 \\
\hline
\end{tabular}

TABLE 4.

POWER EFFICIENCY RESULT (VF $=50 \mathrm{~V})$

\begin{tabular}{|c|c|c|c|c|c|c|}
\hline No. & V.in (V) & RPM & $P_{\text {.in }}(W)$ & Ia.Ra & $\mathrm{Ia}^{2} \cdot \mathbf{R a}$ & If $f^{2} . \mathrm{Rf}$ \\
\hline A-0 & 0 & 957 & 0 & 0 & 0 & 0 \\
\hline A-1 & 10 & 994 & 130.80 & 11.2 & 31.36 & 11.26 \\
\hline A-2 & 15 & 993 & 143.68 & 12.16 & 36.97 & 11.26 \\
\hline A-3 & 20 & 1025 & 160.91 & 13.48 & 45.43 & 11.26 \\
\hline A-4 & 25 & 1030 & 174.84 & 14.44 & 52.13 & 11.26 \\
\hline A-5 & 30 & 1046 & 185.20 & 15.04 & 56.55 & 11.26 \\
\hline No. & $V_{\text {.in }}(\mathrm{V})$ & Ea $(W)$ & Torque (Nm) & RPS & $P_{\text {out }}(W)$ & Efficiency \\
\hline $\mathrm{A}-0$ & 0 & 0 & 0 & 0 & 0 & 0 \\
\hline A-1 & 10 & 29.80 & 31.66 & 2.64 & 88.18 & $67.4 \%$ \\
\hline A-2 & 15 & 29.84 & 34.45 & 2.63 & 95.45 & $66.4 \%$ \\
\hline A-3 & 20 & 29.52 & 36.60 & 2.72 & 104.22 & $64.8 \%$ \\
\hline A-4 & 25 & 29.56 & 39.07 & 2.73 & 111.45 & $63.7 \%$ \\
\hline A-5 & 30 & 29.96 & 40.62 & 2.77 & 117.39 & $63.4 \%$ \\
\hline
\end{tabular}

\section{H. Propeller Curve}

The motor propeller matching can be gain with the propeller curve and the motor envelope. The certain propeller curve is to be fitted to the motor envelope created with loaded condition $\mathrm{P}_{\text {out }}$ VS. RPM graph.
The propeller curve is the summary of engine propeller matching calculation which being calculated and fitted with assumption information of sister ship principal dimension. It produces n-BHP relation curve like shown in the Figure 5. 
International Journal of Marine Engineering Innovation and Research, Vol. 2(1), Dec. $2017.08-15$ (pISSN: 2541-5972, eISSN: 2548-1479)

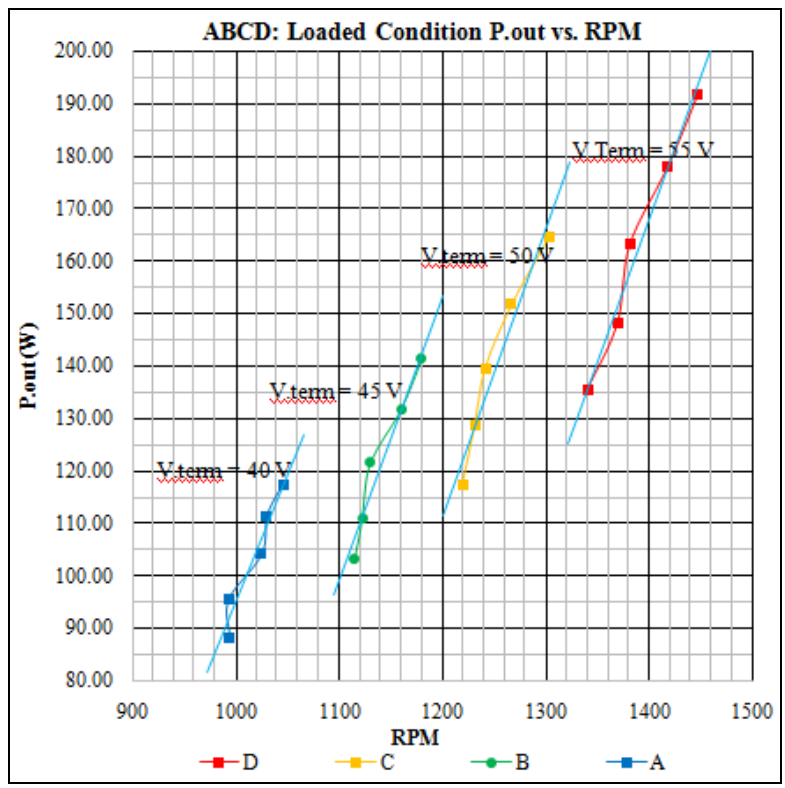

Figure. 3. Loaded Condition $\mathrm{P}_{\text {out }}$ vs. RPM Graph (I.F 0.32 A)

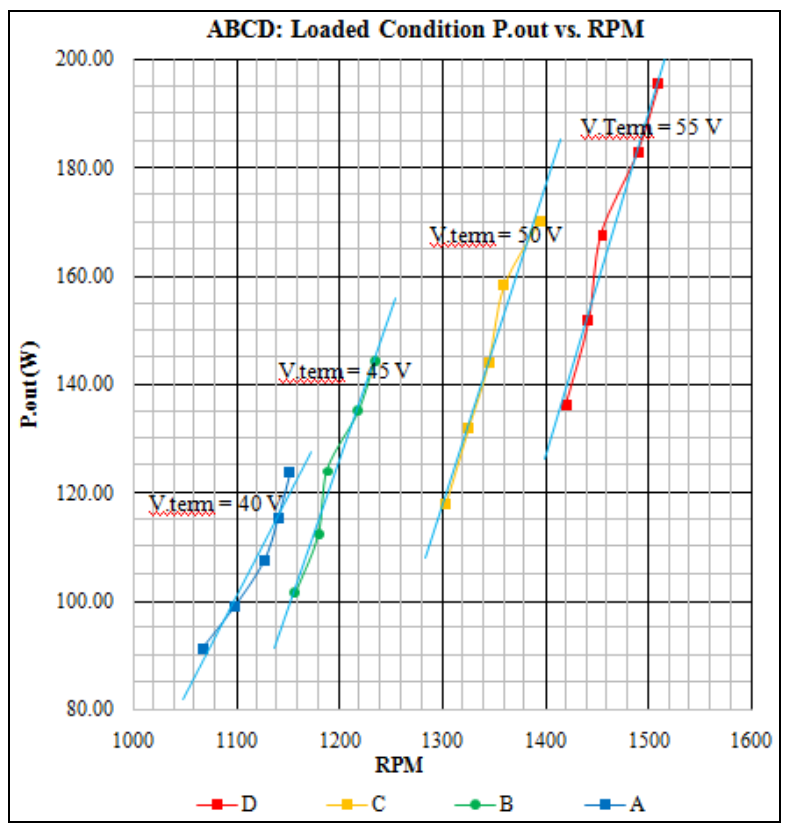

Figure. 4. Loaded Condition $\mathrm{P}_{\text {out }}$ vs. RPM Graph (I.F $0.38 \mathrm{~A}$ )

TABLE 5 .

EXAMPLE VESSEL SPECIFICATION

\section{TYPE: DRY BULK CARRIER}

\begin{tabular}{lll}
\hline Gross Tonnage & 3980 & $\mathrm{ts}$ \\
\hline Net Tonnage & 2474 & $\mathrm{ts}$ \\
\hline Displacement & 8575 & $\mathrm{kt}$ \\
\hline DWT & 6437.94 & $\mathrm{kt}$ \\
\hline Draught (T) Max. & 6.98 & $\mathrm{~m}$ \\
\hline Speed (v) Max. & 12 & $\mathrm{knots}$ \\
\hline LOA & 105.61 & $\mathrm{~m}$ \\
\hline LPP & 98.6 & $\mathrm{~m}$ \\
\hline Breadth & 16.33 & $\mathrm{~m}$ \\
\hline Height & 8.4 & $\mathrm{~m}$ \\
\hline M/E BHP & 3900 & $\mathrm{HP}$ \\
\hline M/E Speed & 230 & $\mathrm{RPM}$ \\
\hline Propeller Blade & 4 & $\mathrm{blades}$ \\
\hline Propeller Diameter & 3.3 & $\mathrm{~m}$ \\
\hline
\end{tabular}




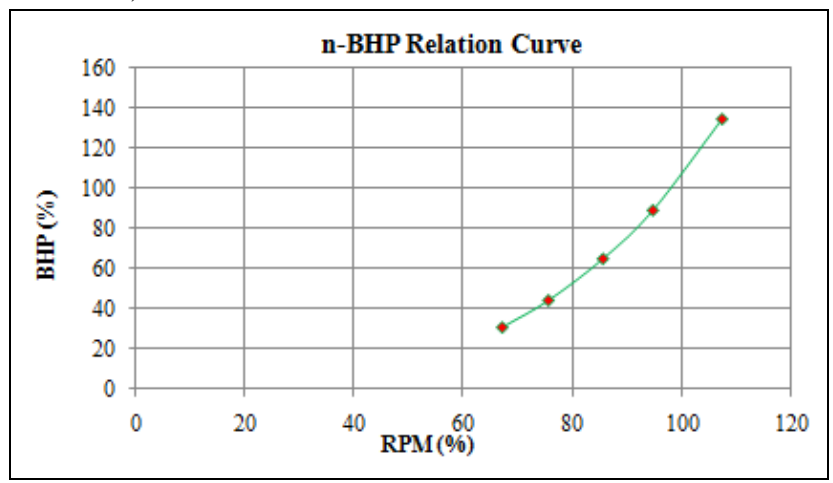

Figure. 5. B4-55 Propeller Curve Graph

\section{Matching Dimensional Analysis}

There is no ambiguity in propeller curve dimensional perspective. It is constructed by the power $(\mathrm{kW})$ and speed (RPM) of its engine which shaped by its power demand in certain operating condition or load. Each point within the propeller curve based on the speed required comes along with resistance a torque required to be produced in it. Meanwhile, different point of view applied for the motor envelope. Its axis comes in the same way as propeller curve, but in different capacity. DC motor not serves information of its maximum capacity in field voltages $50 \mathrm{~V}$, neither $60 \mathrm{~V}$.

Its capacity is possible to be expand until its maximum field voltage and terminal voltage based on certain technical specification of the motor itself. Unlike the motor envelope, propeller curve has certain maximum value of percentages based on its maximum capacity of the engine driven. It is essential to assume the maximum point of each motor envelope, with field voltage $60 \mathrm{~V}$ data as the highest point $(100 \%)$ and field voltage $50 \mathrm{~V}$ is in accordance to $60 \mathrm{~V}$ as maximum percentage. Table 6 serves the sample of field voltage $60 \mathrm{~V}$ assumption to gain percentages value of the motor envelope.

\section{J. Motor Propeller Matching}

The propeller curve is to be shaped to the motor envelope of field voltage 50 volt and 60 volt. Shown below the matching with those graph.

The motor envelope developed from the variable of the calculated The Figure 6 shows the motor and propeller matching in percentage of speed (RPM) in X axis and rated power $(\mathrm{kW})$ in $\mathrm{Y}$ axis. The percentage of speed and power of the motor comes from the comparison of the value of each point to collected data. It does not represent the $100 \%$ of the motor real power due to comparison purposes only.

Meanwhile, the percentage of speed and power of the propeller comes from the engine propeller matching calculation with an assumption ship particular data referred to one example of vessel.

With condition of field voltage 60 volt as maximum and terminal voltage starting from 40 to 55 volt, propeller curve cross over certain section in motor envelope.

The orange area stands for 60 volt field voltage condition with constant current of 0.38 ampere and 30 volt input voltage. It can be seen the rated speed of the vessel in 12 knots is acceptable inside its operating area. Whilst the blue area stands for 50 volt field voltage condition. It comes in constant current of 0.32 ampere and 30 input voltage. One stop speed below rated speed, which define with 11 knots, is critically still within its operating area. The matching curve indicates that the certain propeller, in this case B4-55 is fitted in 60 volt field voltage operating area. It capable to serves the service speed of the vessel within around 12 knots.

The extension line in the graph is the trend line extrapolation of the motor envelope created by the pattern serves by the collected data with condition of field voltage of 50 volt and 60 volt and terminal voltage gradually from 40 until 55 volt. It shows the possible path created by the motor in constant field voltage and further increase of terminal voltage. It is legibly that the motor capable to serves until more than $110 \%$ or 20 points further in this field voltage condition. That condition would be acceptable for another types of propeller which carries different speed-power curve characteristic and or even same types of propeller in larger power demand.

TABLE 6.

Motor EnVElope PERCENTAges AsSUMPtion For V.F. 60 VOLt

\begin{tabular}{|c|c|c|c|c|c|c|c|c|}
\hline \multirow[b]{2}{*}{ No. } & \multicolumn{2}{|c|}{ A: V.Arm start 40} & \multicolumn{2}{|c|}{ B: V.Arm start 45} & \multicolumn{2}{|c|}{ C: V.Arm start 50} & \multicolumn{2}{|c|}{ D: V.Arm start 55} \\
\hline & RPM & $P_{\text {out }}(W)$ & RPM & P.out (W) & RPM & $\mathbf{P}_{\text {out }}(\mathrm{W})$ & RPM & $P_{\text {out }}(W)$ \\
\hline A-1 & 1068 & 91.32 & 1157 & 101.47 & 1304 & 118.01 & 1420 & 136.33 \\
\hline A-2 & 1098 & 98.90 & 1180 & 112.37 & 1326 & 132.05 & 1442 & 151.76 \\
\hline A-3 & 1127 & 107.42 & 1189 & 124.29 & 1345 & 143.89 & 1454 & 167.60 \\
\hline A-4 & 1141 & 115.18 & 1218 & 135.17 & 1360 & 158.25 & 1490 & 182.88 \\
\hline $\mathrm{A}-5$ & 1152 & 123.78 & 1235 & 144.33 & 1395 & 170.09 & 1510 & 195.43 \\
\hline$\%$ & RPM & $P_{\text {out }}(W)$ & RPM & P.out (W) & RPM & $P_{\text {out }}(W)$ & RPM & $P_{\text {out }}(W)$ \\
\hline A-1 & 71 & 47 & 77 & 52 & 86 & 60 & 94 & 70 \\
\hline A-2 & 73 & 51 & 78 & 57 & 88 & 68 & 95 & 78 \\
\hline A-3 & 75 & 55 & 79 & 64 & 89 & 74 & 96 & 86 \\
\hline A-4 & 76 & 59 & 81 & 69 & 90 & 81 & 99 & 94 \\
\hline A-5 & 76 & 63 & 82 & 74 & 92 & 87 & 100 & 100 \\
\hline
\end{tabular}




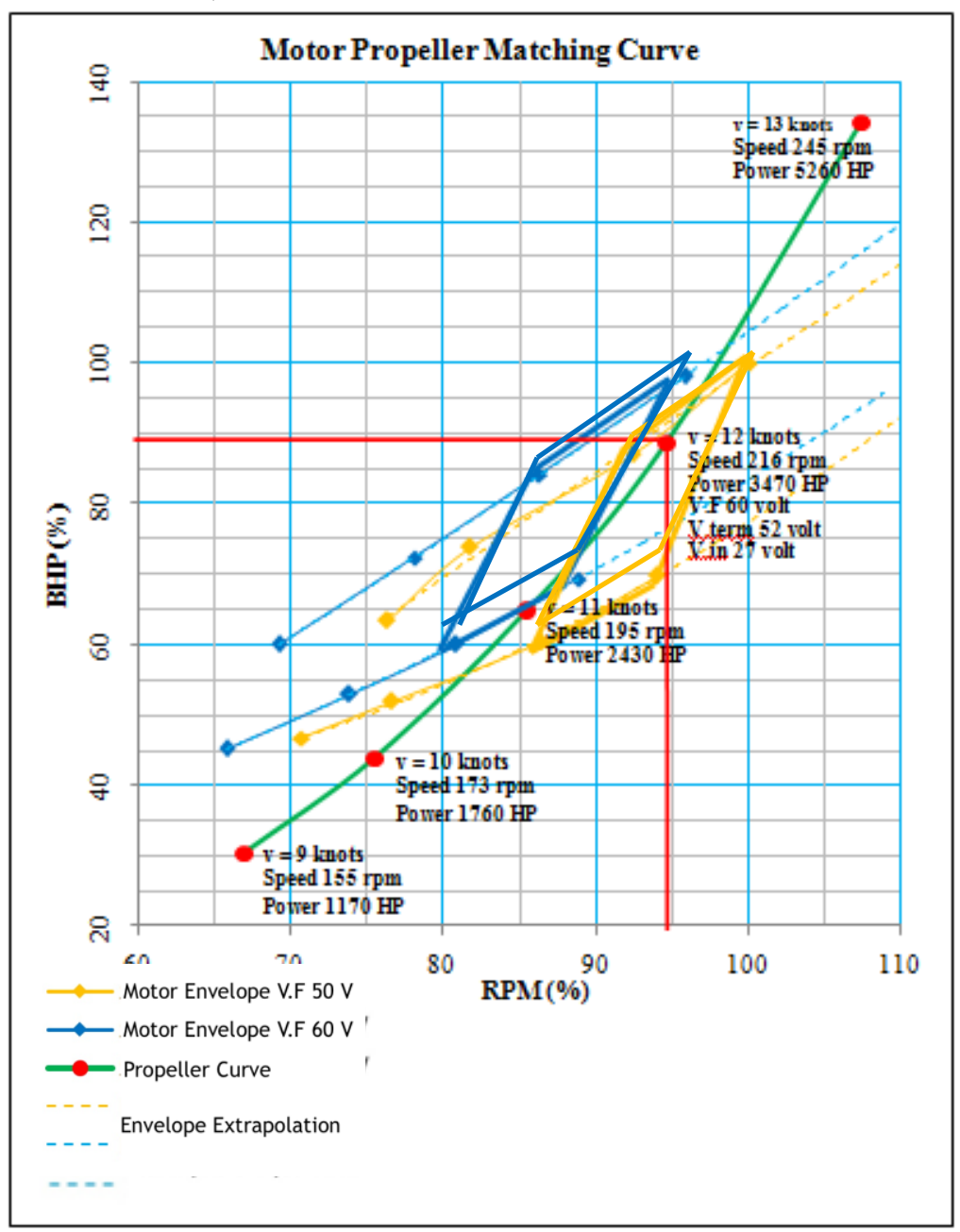

Figure. 6. Motor Propeller Matching (I.F 0.32 and 0.38 A)

\section{CONCLUSION}

To analyze the correlation of separately excited DC motor as main propulsion in engine propeller matching, or in this specific case named motor propeller matching. Within the laboratory scale, it combines the characteristic of DC motor merged to the product of engine propeller matching; the propeller curve. Using the perspective of dimensional, motor propeller matching can be acquired. It results an answer to the problem formulation of this study in the way of laboratory scale. Respective conclusion stated by these points below.

Torque produced by the DC motor is in the same magnitude with the speed (RPM). The higher the speed have shaped the value of the torque.

The speed (RPM) itself is possible to be increase due to the addition of input voltage. It is in the same manner affect the terminal voltage (V.term) and field current (I.F). The current, whether terminal or field, regulated directly to its voltages. Whilst, the terminal and field current will change according to input voltage. Then, all magnitude of those variables will affect respectively the power. It can be explained by variables constructed the power is current and voltage, from both, terminal and field.

Torque is the product of the speed (RPM), but in addition dependence to electromotive force (emf) and terminal current (I.term). The graphical result of torque vs. terminal current is likely in polynomial form. The same way with torque vs. RPM curve. Indeed, it is possible to comprehend the tendency of the torque vs. $\mathrm{RPM}$ to $\mathrm{X}^{2}$ graphical representation. Besides, the torque vs. terminal current progression to linear curve. Torque versus RPM graph shown error in proportion its trend line curve. In the graph of 50 volt of field voltage and constant 0.32 ampere field current shows maximum error of $5.4 \%$. Whilst 60 volt of field voltage and constant 0.38 ampere field current shows maximum error of $3.7 \%$. It indicates the higher the field voltage in accordance to its maximum input voltage of operation, the lower the error acquired.

In the same manner as previous points stated. The input and terminal voltages adjusts all variables and results. In this study, different field voltage creates different pattern of motor envelope. Its manner to propeller curve occurs total different results. With field voltage of $50 \mathrm{~V}$, the ranges of motor envelope immoveable in the point of $150 \%$ of present speed and $160 \%$. While field voltage of $60 \mathrm{~V}$ serves larger ranges of motor envelope which possible to reach further than $50 \mathrm{~V}$ curve.

It concluded that the higher the field voltage, with the same input voltage, could produces different result due to the increasing of other variables, such as; current and voltage, of terminal and field. Noticed that the capacity of the motor in this study, laboratory scale, is much limited than actual study case scale. Apart from that 
condition, the extensive ranges of motor envelope or motor working condition area can affect the matching section with certain propeller curve based on certain propeller type.

\section{REFERENCES}

[1] Chapman, Stephen, "Electric Machinery Fundamentals 5th Edition", McGraw-Hill Higher Companies, ISBN 978-0-07352954-7, New York, USA, 2005.

[2] Fitzgerald, A. E.; Kingsley, Charles; \& Umans, Stephen, "Electric Machinery 6th Edition", McGraw-Hill Higher Education Publishing, ISBN 0-07-366009-4, New York, USA, 2003.

[3] Kusuma, Indra Ranu., Koenhardono, Eddy Setyo., Karmina, Riantiti. 2016. Design of Protection Coordination for Overcurrent on Electrical System in Tanker Ship Plan using Electro Mechanical Trip Device.. International Journal of Marine Engineering and Innovation Research.

[4] Koenhardono, Eddy Setyo., Amiadji., Kristomi, Rahmat. 2016. The Study of the Application of Hybrid Propulsion System on OPV with Controllable Pitch Propellers. International Journal of Marine Engineering and Innovation Research.

[5] Kurniawan, Adi., Koenhardono, Eddy Setyo., Kusuma, Indra Ranu., Hardianto. 2015. Modeling and control of ballast system to improve stability of catamaran boat. International Conference on Advanced Mechatronics, Intelligent Manufacture And Industrial Automation.

[6] Jaelani, Lalu Muhamad., Koenhardono, Eddy Setyo., Pamungkas, Adjie., Sulisetyono, Aries. 2016. Estimation of TSS and Chl -a Concentration from Landsat 8-OLI: The Effect of Atmosphere and Retrieval Algorithm.

[7] Theraja, B. L.; Theraja, A. K.; \& Tarnekar, S. G., “A Textbook of Electrical Technology Vol. I and II", S Chand \& Company Ltd., ISBN 81-219-2440-5, New Delhi, India, 2005.

[8] Doorduin, Willem, "The Use of Electric Motors for The Propulsion of Seagoing Vessels", Rotterdam Mainport University of Applied Sciences (RMU), 2013.

[9] Hughes, Edward, "Electrical and Electronic Technology 10th Edition", Pearson Education Inc., ISBN 978-0-13-206011-0, London, 2008.

[10] Tupper, E. C., "Introduction to Naval Architecture 4th Edition", Elsevier Ltd., ISBN 0-7506-6554-8, Oxford, 2004.

[11] Wildi, Theodore, "Electrical Machines, Drives, and Power Systems 6th Edition", Pearson Education Inc., ISBN 0-13-177693-2, New Jersey, 2006 